\title{
Erratum to: Laparoscopic vs. open surgery for treating benign liver lesions: assessing quality of life in the first year after surgery
}

\author{
Antonio Giuliani - Carla Migliaccio • \\ Antonio Ceriello • Giuseppe Aragiusto • \\ Giuseppe Lamanna $\cdot$ Fulvio Calise
}

Published online: 20 May 2014

(C) Springer-Verlag Italia 2014

\section{Erratum to: Updates Surg}

\section{DOI 10.1007/s13304-014-0252-5}

Unintentionally, the author Giuseppe Lamanna's family name and his affiliation were wrongly published in the original publication. The correct family name and his affiliation are given below.

\section{G. Lamanna}

Department of Industrial and Information Engineering, Second University of Naples,

via Roma 29, 81031 Aversa, Italy

The online version of the original article can be found under doi:10.1007/s13304-014-0252-5.

\footnotetext{
A. Giuliani - C. Migliaccio - A. Ceriello - G. Aragiusto · F. Calise

Unit of Hepatobiliary Surgery and Liver Transplant Center, Department of Transplantation, Cardarelli Hospital, via Cardarelli, 9, 80131 Naples, Italy

A. Giuliani $(\square)$

via Bruno Falcomatà, 5, 80128 Naples, Italy

e-mail: giuldoc@hotmail.com

G. Lamanna

Department of Industrial and Information Engineering, Second

University of Naples, via Roma 29, 81031 Aversa, Italy
} 